\title{
Effect of visual cues on a 1-trial passive avoidance response
}

\author{
RONALD P. GRUBER, Biophysics \\ Laboratory, Edgewood Arsenal, Md. 21010
}

An attempt was made to demonstrate fear conditioning to visual cues in a one-trial passive-avoidance situation. Ss received shock of one of two intensities in the black compartment of a black-white shuttlebox. Subsequently, Ss were tested to either the original black or a new white compartment. No significant differences in the latencies of responses to black or white compartments were noted by either shock-level group. Thus, under the present conditions, fear conditioning to visual cues in a one-trial passive-avoidance situation could not be demonstrated.

Passive-avoidance responding (PAR) has generally been thought of as a conditioned instrumental response with the possible component of a classical conditioned-fear response to environmental cues. Supporting the notion that at least part of the PAR involves classical fear conditioning, Blanchard \& Blanchard (1969) demonstrated that crouching is elicited by stimulus cues associated with a single shock. It has also been demonstrated that a one-trial PAR may be conditioned to a buzzer CS (Gruber, unpublished data). Similar results with a light $C S$ were not obtainable. However, Randall \& Riccio (in press) provided evidence for a onetrial PAR to visual cues. They noted that the PAR was better extinguished by placing $S$ in the same black compartment in which he received shock than by placing him in a white compartment. Thus, it seems reasonable to predict that $S$ will avoid the black (shock) compartment more than the white (nonshock) compartment. This study intended to test that possibility and support the notion that fear can be conditioned to visual cues in a one-trial PAR.

\section{SUBJECTS AND APPARATUS}

The Ss were $42 \quad \mathrm{male}$ Sprague-Dawley-Wistar rats, weighing 190-210 g. The apparatus was a $22 \times 10 \times 6$ in. shuttlebox divided by a $4 \times 6$ in. guillotine door into white and black compartments. The black compartment could be made white by changing cardboard inserts. The grid of the black compartment could be charged with 0.5 or $2.0 \mathrm{~mA}$ from a Grason-Stadler Model E1064GS shock apparatus. Background noise and light were provided by an overhead fan and a 6-W bulb, respectively. A mirror, mounted overhead, permitted continuous observation of $S$. PROCEDURE

Training consisted of placing $S$ in the white compartment facing away from the closed door. Ten seconds later, the door was opened, and $\mathrm{S}$ was allowed to cross into the black compartment. When $S$ finally crossed (four-paw criterion), the door was closed, and a 1-sec inescapable 0.5 - and $2.0-\mathrm{mA}$ shock was administered. Immediately thereafter, $S$ was transferred to a "hold" cage for $30 \mathrm{~min}$. Testing consisted of placing $S$ in the white compartment facing away from the now-open door. However, the black compartment was now white for half the Ss. The latency to enter the black or white compartment was then recorded. Thus, there were two groups each receiving one of two shock intensities. Each group was tested to either the black or white compartment. A control group of $10 \mathrm{Ss}$ did not receive shock, but half were tested to the black and half to the white compartment.

\section{RESULTS}

The mean latency of each group to the black or white compartment under both shock conditions is recorded in Fig. 1. An analysis of variance indicated that there was no preference for black or white by the control group. The latencies of the 2.0-mA group was greater than that of the $0.5-\mathrm{mA}$ group, which was greater than that of the control group $(p<.01)$. While the latency to the black compartment was greater than that to the white compartment by the $0.5-\mathrm{mA}$ group, the difference was not statistically significant. The latency of the $2.0-\mathrm{mA}$ group to the white compartment was in fact greater than that to the black compartment but, again, not statistically significant. The slopes of all three groups did not have a significant interaction.

\section{DISCUSSION}

The fact that the latencies to both black and white compartments were not significantly different would seem to indicate that fear was not conditioned to visual cues. On the other hand, it is possible that visual-cue conditioning was acquired but was not apparent in the testing situation used. It is possible that one of the following factors overshadowed the cue effect: (1) fear to the entire environmental situation, (2) the instrumental aspect of conditioning, or

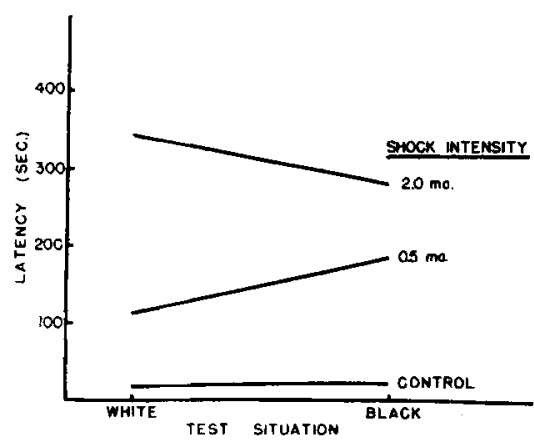

Fig. 1. Mean latencies to the black or white compartment following a single shock in the black compartment for two shock-intensity groups. Control group received identical training with the exclusion of shock.

(3) persistent freezing. The greater trend toward the anticipated results by the lower-shock-intensity group would be consistent with this notion. Increasing shock intensity results in more freezing and greater generalized fear reactions, both of which could obscure visual-cue effects. Differences in extinction rates to visual cues, as used by Randall and Riccio, may be a more sensitive index of discrimination because, during the process of extinction, the fear and freezing components weaken. Although less likely, the difference in rat strains may be a factor. Black-white preferences are unlikely to account for the present results since there was no such preference in the control group. One cannot conclude from this study, however, that fear conditioning did not occur to visual cues, but merely that, under the circumstances described, it could not be demonstrated.

The mean latencies of all groups in this experiment were much shorter than the $500-\mathrm{sec}$ latency in Randall and Riccio's experiment. This is probably related to the difference in species and to the difference in apparatus. The longer latency of the $2.0-\mathrm{mA}$ group over the $0.5-\mathrm{mA}$ group is consistent with the findings of Blanchard \& Blanchard (1968) and is attributed to a difference in motivation.

\section{REFERENCES}

BLANCHARD, R. J., \& BLANCHARD, D. C. Escape and avoidance responses to a fear eliciting situation. Psychonomic Science, 1968, 13, 19-20.

BLANCHARD, R. J., \& BLANCHARD, D. C. Crouching as an index of fear. Joumal of Comparative \& Physiological Psychology, 1969, 68, 129-135.

RANDALL, P. K., \& RICCIO, D. C. Fear and punishment as determinants of passive avoidance responding. Journal of Comparative \& Physiological Psychology, in press. 